\title{
Build it. But where? The use of geographic information systems in identifying locations for new cycling infrastructure
}

\author{
Jacob Larsen \\ PhD Student \\ School of Urban Planning \\ McGill University \\ Suite 400, 815 Sherbrooke St. W. \\ Montreal (QC) H3A 2K6 \\ Canada \\ Tel.: 514-398-4058 \\ Fax: 514-398-8376 \\ E-mail: jacob.larsen@mail.mcgill.ca \\ Zachary Patterson \\ Assistant Professor \\ Department of Geography, Planning and Environment \\ 1455 de Maisonneuve W., H 1255-26 (Hall Building) \\ Montreal (QC) H3G 1M8 \\ Canada \\ Tel.: (514) 848-2424 ext. 3492 \\ Fax: (514) 848-2032 \\ E-mail: zachary.patterson@concordia.ca
}

\author{
Ahmed M. El-Geneidy \\ Assistant Professor \\ School of Urban Planning \\ McGill University \\ Suite 400, 815 Sherbrooke St. W. \\ Montreal (QC) H3A 2K6 \\ Canada \\ Tel.: 514-398-8741 \\ Fax: 514-398-8376 \\ E-mail: ahmed.elgeneidy@mcgill.ca
}

For Citation please use: Larsen, J., Patterson, Z., \& El-Geneidy, A. (2013). Build it. But where? The use of geographic information systems in identifying locations for new cycling infrastructure. International Journal of Sustainable Transportation, 7(4), 299-317. 


\section{Introduction}

As problems with urban congestion and concern over air quality increase, so too has interest grown in encouraging utilitarian cycling for short distance trips. Many North American cities have begun initiatives to implement new on-street and off-street cycling facilities, yet much progress must be made to complete networks that provide safe, efficient access to multiple destinations. In Montreal, the case study city examined in this paper, the recent transportation plan calls for a doubling of existing cycling infrastructure (Montréal 2007). Despite a fast growing literature on cycling in the transportation and transportation planning literature, there has been surprisingly little research on how to decide how to prioritize and choose locations for cycling infrastructure investments.

This paper begins to fill this void by presenting a GIS-based, grid-cell model for bicycle facility prioritization and location. The model provides the flexibility to include various relevant, readily-available data sources in an easily interpretable graphical format suitable for decisionmakers and the public. The main result is a grid-cell layer of the study region where high-priority grid-cells represent those areas most appropriate for bicycle infrastructure interventions. In the example provided here, high-priority grid-cells represent areas where new cycling facilities would provide the maximum benefit to both existing and potential cyclists.

The method presented is not intended to be the only tool used by transportation planners in bicycle facility planning. Moreover, the paper does not suggest that bicycles only belong on certain streets. Rather, the paper presents a tool which may be strategically employed in cities where cycling facilities are limited and efforts to develop new facilities are slow. While the tool could be applied in isolation, it would be much more effectively applied in the context of a broader planning process with clearly articulated objectives. Within such a context, the tool could effectively be used to prioritize and select different infrastructure investment scenarios.

The paper begins with a review of the literature on bicycle transportation and on the methods previously used in locating various types of facilities. The second section describes cycling infrastructure in the study region - the Island of Montreal. The third section introduces the data sources used in the proposed methodology. The following section describes and explains the 
methodology used for locating new bicycle facilities, while drawing on the relevant literature on bicycle infrastructure planning, and illustrates how it was applied for the case of Montreal. The final section provides a discussion and conclusions relevant to Montreal specifically, and cities more generally, as well as the identification of opportunities for future research in this field.

\section{Literature Review}

Since the mid-1990s there has been an explosion of interest and research in the transportation and transportation planning literatures on cycling. This research generally falls into four streams. The first stream of research has looked at cycling infrastructure from the perspective of their costs and benefits from a public investment perspective (Hopkinson and Wardman 1996; Ortuzar, Iacobell et al. 2000; Krizek 2007).

The second and largest stream of research has aimed to better understand how different facilities and environments affect cyclists' travel behavior. Most of this research has found that cycling infrastructure has a positive effect on cycling. For example, (Nelson and Allen 1997; Dill and Carr 2003) involved cross-sectional studies of multiple cities - both with and without extensive networks of cycling lanes - and showed that the share of cyclists grows as appropriate facilities are provided. (Cervero, Sarmiento et al. 2009; Larsen and El-Geneidy 2011) have found that the presence of bicycle lanes or paths directs cyclists onto certain routes. Similarly (Krizek, ElGeneidy et al. 2007), in a study in the Twin Cities region, found that cyclists added, on average, $51 \%$ to their total trip length to use high-quality, off-street cycling facilities. While the majority of research has found a positive relationship between cycling infrastructure and cycling, this has not been unanimous. Others (Aultman-Hall, Hall et al. 1997; Moudon, Lee et al. 2005) have

found the presence of cycling infrastructure to be insignificant in promoting cycling in general or in redirecting cyclists in particular.

A third stream of research has suggested that the installation of cycling infrastructure alone is likely to prove insufficient in attracting new cyclists (Handy and Xing 2011; Noland, Deka et al. 2011). Indeed, the lack of adequate bicycle infrastructure is but one of the reasons typically cited as a barrier to cycling (Baromètre 2005; Parkin, Ryley et al. 2007). Moreover, "soft measures" such as cyclist education, driver training and promoting a culture in which cycling is a normal 
mode of transportation have been cited as having an important role as well (Pucher, Komanoff et al. 1999).

A fourth stream of research into cycling in the transportation literature has been concerned with safety issues related to cycling facilities. A heated debate on whether on-street bicycle facilities should exist at all. On the one hand, it has been argued that cyclists can easily ride in mixedtraffic conditions, and a false sense of security is derived from bicycle facilities, and thus there is no need for on-street "bikeways" (Forrester 2001). On the other hand, there is growing evidence that the perception of danger will discourage the use of the bicycle as transportation, even if the danger level is not necessarily higher (Garrarda, Roseb et al. 2008). Some have considered safety issues (both real and perceived) surrounding specific types of cycling facilities. (Landis, Vattikuti et al. 1997; Jensen 2007). Moreover, a recent study of segregated facilities in Montreal - one of few North American cities to use this type of facility - suggests that riding in segregated bicycle facilities can have better observed safety outcomes than riding in mixed traffic (Lusk, Furth et al. 2011). However, this study also notes that there are certain streets where segregated facilities may have the opposite effect, though these findings were not statistically significant.

What is most surprising about the existing transportation literature on cycling, especially given the interest and political will in investing in cycling facilities, is the absence of research into how to systematically prioritize and locate facilities that are to be built. This paper proposes a GIS based model to address this absence. Despite the absence of such methods in the cycling literature, this approach does not come out of the blue. Geographical information systems (GIS) have been employed to assist in identifying the sites for locating various types of new facilities both in urbanized and non-urbanized situations. In the context of transportation infrastructure, researchers have used a GIS to visualize derived demand to objectively identify suitable locations for park-and-ride facilities along urban rail corridors (Horner and Grubesic 2001). Moreover, researchers from various disciplines have used GIS in a wide variety of locationallocation problems (Yeh and Chow 1996; Ryan and Getz 2005). As such, the work presented here draws on literature using GIS for planning other types of transportation infrastructure, and uses it to fill a gap in the existing transportation planning literature on cycling. 


\section{Study Area}

Montreal, Québec is the second most populous metropolitan area in Canada with a population of 3.7 million people. Montreal has a total of 425 kilometers of cycling facilities (Fig. 1) of which 264 kilometers are off-street facilities and 161 kilometers are on-street. In Montreal, like many other North American cities that installed bicycle paths post 1970s, these amenities were initially intended to serve recreational purposes (Pucher 2008). More recently, pressure from advocacy groups and an increasing acceptance of bicycles as a legitimate form of urban transportation has resulted in the development of some on-street facilities. However, these two approaches have led to a largely disconnected cycling network, often consisting of isolated segments that are poorly adapted to serve utilitarian trip purposes. As cycling levels increase in many North American cities, the need for a systematic method to locate new cycling facilities is growing ever more necessary.

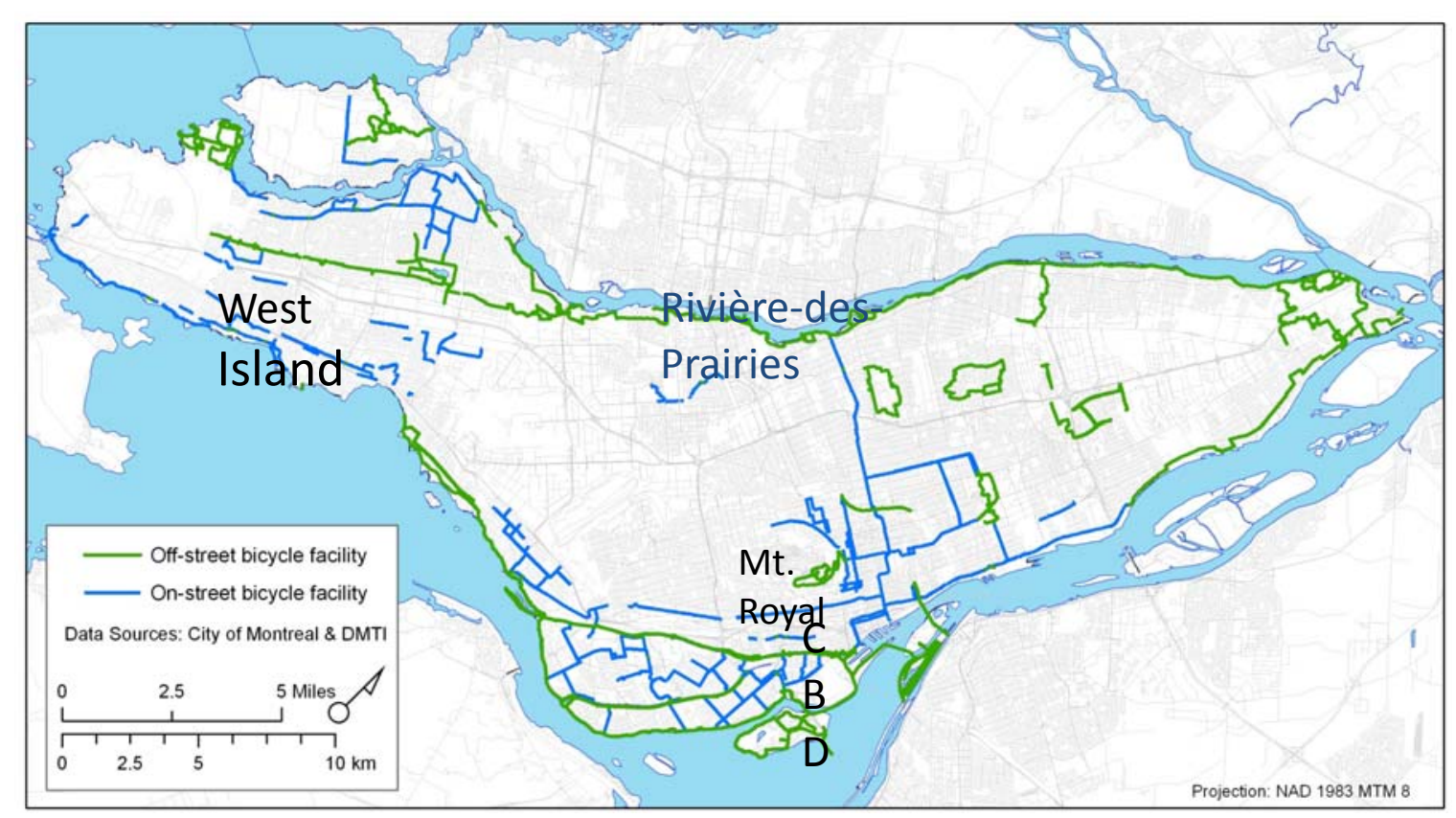

Figure 1. Map of Montreal's on- and off-street bicycle facilities

Within the categories of on-street and off-street bicycle facilities, several different design styles can be found in Montreal, making that city a promising location to explore performance characteristics of different cycle route types. These include separate, off-street facilities (Fig. 2a), on-street striped lanes (Fig. 2b), 'sharrow markings' (Fig. 2c), and physically-separated, 
bidirectional on-street lanes (Fig. 2d). While many of these facilities are continuous, there are significant discontinuities in the network, which are considered later in the analysis as an indicator for prioritizing the need for future investments.

\section{A) Off-streetpaths}

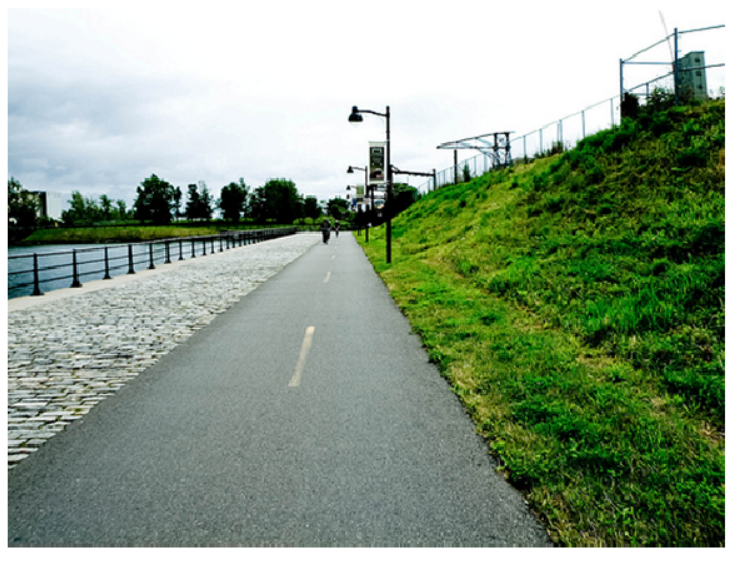

C) On-streetsharrows

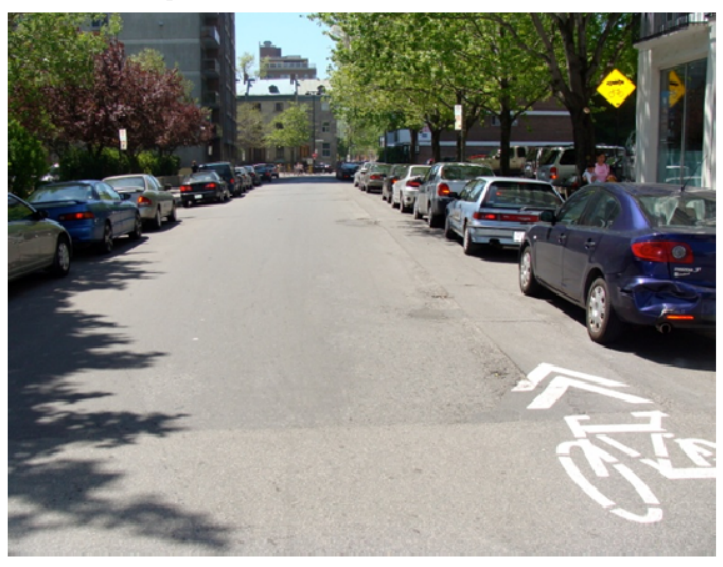

B) On-street painted line

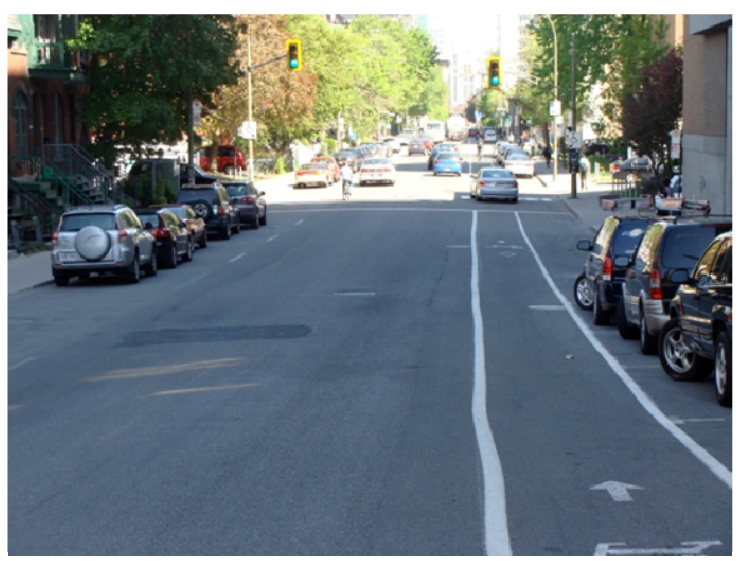

D) On-street, physically-separated, bldirectional

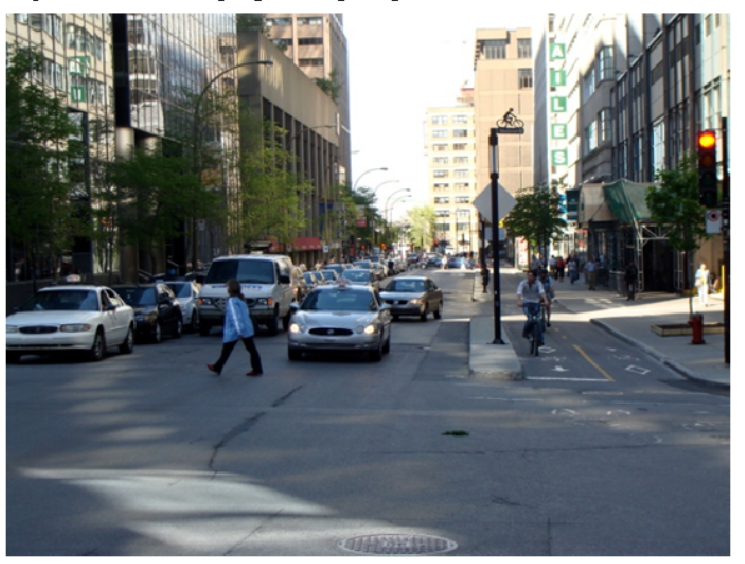

Figure 2. Examples of cycling facilities in Montreal

\section{Data Sources}

The data used in this analysis came from three different sources. The first was an online survey of cyclists, administered in the summer of 2009 (Larsen 2010). It asked cyclists for three types of information. An initial section asked respondents for socio-demographic information. Another section on cycling behavior asked about usual bicycle origin and destination, bicycle path availability and whether any bicycle paths were used during the usual bicycle trip. The following section asked respondents about their preferences with respect to different cycling infrastructure 
configurations, as well as bicycle route and intersection characteristics. Finally, and most pertinent for the present analysis, it asked where new bicycle paths were needed. This was accomplished by asking respondents to specify which street most needed a cycling facility, including the cross street where it should begin and the cross street where it should end.

The survey was publicized widely in online newsletters, print and online media, online social networking sites and by distributing flyers directly to cyclists. Ultimately, the survey was completed by nearly 3,000 respondents, representing the largest detailed survey of Montreal cyclists to date. Online surveys are frequently cited for sampling biases, due to coverage issues and sample size (Dillman, Smyth et al. 2009). The extensive outreach conducted for this survey may compensate for coverage issues; however the total population of Montreal cyclists remains unknown, so despite the large sample size, the minimum sample size for this population is not known.

The second source of data for this study came from the public automobile insurance agency, the Société de l'assurance automobile du Québec (SAAQ) and involved vehicle collision data from 2003 through 2008. Altogether the database had records for 152,820 collisions of which 2,075 were bike-vehicle collisions. Six of these accidents were fatal and 1,050 resulted in injuries.

The third source of data was the Montreal Origin-Destination (OD) survey. The Montreal OD survey is a particularly large and rich OD survey. It is conducted every five years, and surveys around 5\% of the households in the region (Agence métropolitaine de transport 2003). It collects socio-demographic information on households including size, location, number of vehicles and income. Demographic information is also collected on individuals in the household, as well as all trips made during the 24 hours of the previous day. Trip information includes all modes (i.e. cycling and walking in addition to motorized modes), as well as each trip segment. For public transit trips, all transit lines used are recorded and for trips using commuter train or metro, boarding and alighting stations are also recorded. Origins and destinations are geocoded to $\mathrm{x}-\mathrm{y}$ co-ordinates. Although data for the entire region were available, this analysis is limited to the Island of Montreal, where the vast majority of cycling trips are made. 


\section{Methodology and Application}

This paper presents an approach to identify and prioritize cycling infrastructure investments using the example of Montreal. The general methodology can be broken into four steps. The first is to identify pertinent indicators (for which data are available) that can be used to prioritize locations for infrastructure investments. The second is to impose a grid and spatially aggregate the pertinent indicators and associate them to the grid's cells. Third, the aggregated grid cell indicators are combined into a 'prioritization index.' The index itself is designed so that the higher the index, the more appropriate is the grid cell as a location for cycling infrastructure investments. Fourth, the prioritization index is mapped to allow for a general analysis of where existing infrastructure is with respect to the highest priority regions (grid cells) for infrastructure investments. Finally, grid cell characteristics, information on existing infrastructure and disaggregate data are combined to infer the most appropriate types of interventions for particular locations.

\section{Identification of Pertinent Indicators}

Although no literature on methods for identifying new locations for bicycle facilities was found, there are a variety of objectives that can be drawn on to identify and prioritize locations for cycling infrastructure investments. Improving access to specific destinations by bicycle, addressing issues of safety concern, and encouraging new cyclists are a few examples mentioned in the existing literature as the stated objectives for new facilities (Ortuzar, Iacobell et al. 2000; Abraham, McMillan et al. 2002; Parkin, Wardman et al. 2007; McNeil 2011). As such, and based on the data available, five indicators were chosen in the method presented below that respond to these objectives.

\section{Observed and Potential Cycling Trips}

The first two indicators were the number of 'observed' and 'potential' cycling trips expected to pass along different links. The data source for these was the OD survey. 'Observed' trips were simply cycling trips identified in the OD survey. There were 3,376 such trips recorded in the OD survey on the Island of Montreal. Here, 'potential' cycling trips were defined as car trips short enough that it was thought they could be replaced by bicycle trips. These were defined as car trips that were shorter than the $75^{\text {th }}$ percentile of cycling trips (approximately $2 \mathrm{~km}$ ). Lacking any guidance in the literature this cut-off $\left(75^{\text {th }}\right.$ percentile) was arrived at empirically. There were 
31,331 car trips on the Island of Montreal that satisfied this criterion and that were therefore considered to be 'potential' cycling trips. This is clearly a crude approximation of trips that could be shifted from car to bike, however there has been little research on the opportunities to reduce short car trips specifically (Mackett 2001). Many factors influence the degree to which a particular trip could realistically be shifted from car to bike, including among others: age, gender, presence of children, etc. A more accurate number of potential trips taking into account these other factors could (and should) be used in a particular application. Since the purpose of this paper is to demonstrate the technique, and since a more accurate number of potential cycling trips is in its own right a topic of research, this simplistic measure is used in this demonstration of the method. This particular indicator focuses on the intended benefits of new infrastructure to current car users making short trips, so the benefits to current cyclists may be limited. These indicators address objectives to improving access to destinations and encouraging new cyclists.

While the OD survey collects detailed information (i.e. line used, boarding and alighting stations) on public transit trips, for other trips there is little information on what routes were used. As a result, if one is interested in the actual infrastructure that was used (in the case of 'observed' trips) or the infrastructure that would be used (in the case of 'potential' trips), it is necessary to model or estimate this. Since $x-y$ coordinates for origins and destinations were available for all trips, the most practical approach was to estimate routes by assigning them using traditional assignment methods. In this case, trips were assigned using the standard shortest path by time (All-Or-Nothing) algorithm with network analyst in ArcGIS, an approach adopted in previous bicycle route choice studies (Aultman-Hall, Hall et al. 1997).

This approach was not perfect. The network that was used was only partially adapted to use for bicycle assignment. In fact, the only modification made to the road network before assigning the trips was to remove highways so that cyclists could not be assigned to them. Link speeds were not adjusted for cyclists, no provision was made for cycle paths and cyclist preference for them, and elevation was not considered (Broach, Gliebe et al. 2011). While each of these additional factors would have likely improved the actual routing of bicycle trips, the development of a bicycle assignment model was outside the scope of the research. As well, the need for such 
precise bicycle assignment was circumvented (as will be described below) by the spatial aggregation of this information through the use of grid cells.

\section{Priority Segments Identified in Cycling Survey}

Asking cyclists to define areas where there is a need for new cycling infrastructure is a useful method for prioritizing the building of these new infrastructures. It was used to obtain the third indicator pertinent to prioritizing locations for new bicycle infrastructure: the identification of specific links by cyclists in the cycling survey. As explained above, respondents to the cycling survey were asked to name streets (including starting and ending intersections) they believed to be the highest priority for bicycle path additions. Naturally, this information is link-specific, but as with links used by 'observed' and 'potential' bicycle trips, was later spatially aggregated to the corresponding grid cell. This indicator also addresses the objectives of improving access to particular destinations (those where people currently go) and encouraging new cyclists.

\section{Cycling Collisions}

Safety is one of the most important decisions affecting cyclists travel behavior and the perception of unsafe cycling conditions deters some people from commuting by bicycle. (Aultman-Hall 1996; Landis, Vattikuti et al. 1997; Hunter, Harkey et al. 2000; Allen-Munley, Daniel et al. 2004). Indeed, opinion polls commissioned by the City of Montreal have revealed that this remains the greatest impediment to attracting new cyclists in Montreal (Baromètre 2005). Cycling facilities in general increase the perception of safety, however real safety improvements depend on a host of other factors, including facility design and motor vehicle volume (Parkin, Wardman et al. 2007). As such, the fourth indicator used was the location of cycling collisions obtained from the SAAQ accident database. These data were geo-coded in GIS allowing the identification of priority areas where interventions would likely improve safety. Unfortunately, it was not possible to account for motor vehicle exposure or cyclist volumes because they were not available in many cases. Also, the accuracy of this method depends mainly on the reliability of recorded bicycle collisions, which often go unreported. This indicator addressed the objectives related to improving safety; however, other indicators related to safety, such as locations known for frequent conflicts between bicyclists and other road users could also be adopted. 


\section{Connecting 'Dangling Nodes'}

Another measure to be considered in the analysis was the issue of discontinuities in the existing network and what degree they should influence the location of new facilities. Examination of a cycling map for many regions, including Montreal, reveals the extent to which cycling infrastructure was built as individual segments and not as a network. Consequently, in most cities with cycling facilities, there are many discontinuities where the path or lane simply ends abruptly (Krizek and Roland 2005). When revising the existing network, it is recommended that planners identify the links in the network that will have the greatest impact on increasing the connectivity of the cycling networks. This can be done identifying locations where cycling facilities endwhich we refer to as 'dangling nodes.' This was the fifth indicator that was considered when prioritizing locations for bicycle infrastructure investments. By prioritizing the connectivity of cycling infrastructure this indicator aims to address the objectives of safety and encouraging new cyclists.

\section{Imposing a Grid and Spatially Aggregating Indicators}

The second step in the methodology was to superimpose a grid over the study region and to associate spatially aggregated characteristics to the grid cells. The primary reason for this approach was to circumvent some of the weaknesses of the assignment method used (see section “Observed and Potential Cycling Trips” above).

Based on the cycling survey, anecdotal information and experience with bicycle routes used by cyclists in Montreal, the shortest-path algorithm used to assign 'observed' and 'potential' cycling trips over-predicted the use of arterials relative local streets and bike paths. This was due to the fact that link speeds for arteries were higher than for local streets and also that the shortest path algorithm did not account for preferences for local streets relative to arteries. While the shortest path approach privileged arteries to local streets, the general pattern of how the trips were assigned seemed reasonable. That is, while the actual streets to which the bicycle trips were assigned were biased towards arterials, the general corridors to which the trips were assigned seemed realistic. A grid cell approach was judged appropriate in this context.

The grid cell approach was adopted in the following manner: the estimated number of 'observed' and 'potential' bicycle trips (assigned by shortest path) were aggregated by grid cell. This 
resulted in the estimated number of bicycle trips passing through each grid cell. The idea was that the more 'observed' or 'potential' cycling trips that passed through a particular grid cell, the better it would be as a location for infrastructure investments. While a grid cell approach was appropriate in this context, it was necessary to test various grid cell sizes. The idea was to choose a grid cell size that would preserve the corridors used (according to the assignment process), but not individual links. After testing several grid cell sizes, and based on network density in the main cycling areas in Montreal, 300m was established as the optimal grid cell size.

The number of priority segments identified in the cycling survey was also aggregated at the gridcell level. Grid cells with more priority segments were deemed to be better locations for infrastructure investments. The number of bicycle-automobile collisions in a given grid cell was the fourth aggregate grid cell characteristic used. Grid cells with more collisions suggested a better location for infrastructure investments to improve safety. The aggregation of four of the five pertinent characteristics was done routinely in ArcGIS. While four of the five indicators were aggregated by grid cell, the final indicator, 'dangling nodes,' was not. Instead, the presence of 'dangling nodes' in a grid cell was incorporated as a subsequent visual analysis. The reason for this is explained in the section "Inclusion of non-aggregated indicators ('dangling nodes')," below.

\section{Calculation of the Prioritization Index}

The third step in the methodology was to summarize aggregated grid cell information in a consistent manner. The approach adopted was to use a 'prioritization index.' The index was designed so that an increase in each of the measurements associated with the grid cells would result in a higher prioritization index score.

The prioritization index was calculated according to the following equations:

$$
x_{i}=\frac{o_{i}}{\sum_{j} o_{j}}+\frac{p_{i}}{\sum_{j} p_{j}}+\frac{\operatorname{col}_{i}}{\sum_{j} \operatorname{col}_{j}}+\frac{\operatorname{pri}_{i}}{\sum_{j} p r i_{j}}
$$

$x_{i}$ in equation 1 is an intermediate value for each grid cell (indexed by i through $\mathrm{j}$ ) representing the sum of four elements, where:

- $\mathrm{O}_{\mathrm{i}}$ denotes the number of 'observed' cycling trips passing through gridcell i 
- $\mathrm{p}_{\mathrm{i}}$ denotes the number of 'potential' cycling trips passing through gridcell $\mathrm{i}$

- $\mathrm{col}_{\mathrm{i}}$ denotes the number of collisions having occurred in gridcell $\mathrm{i}$

- pri $_{i}$ denotes the number of times a link in grid cell i was identified by survey respondents as being a priority link for upgrading

As such, each element is the overall percentage for a given measurement (e.g. potential trips) represented by grid cell $\mathrm{i}$.

$$
P I_{i}=\frac{x_{i}}{\sum_{j} x_{j}}
$$

Equation 2 represents the final prioritization index. It is simply grid cell i's percentage of $x_{i}$ relative to the rest of the grid cells. Naturally, the higher the prioritization index, the higher the priority a grid cell is ascribed in terms of the addition of cycling infrastructure. The prioritization index as formulated here gives equal weight to all factors; however this may be adjusted if more emphasis were deemed necessary for particular characteristics. That each pertinent grid cell characteristic here has the same weighting in the index is not to suggest that they should have equal weighting, only that for the purpose of demonstrating the method, equal weighting was assumed. Indeed, in application it would be suitable for analysts to develop a weighting scheme appropriate to the particular application (see below for more on this).

\section{Inclusion of non-aggregated indicators ('dangling nodes')}

As mentioned above, unlike the other indicators, the indicator identifying the presence of 'dangling nodes' was not aggregated by grid cell. The reason for this is that unlike the other indicators, the presence of dangling nodes was not sufficient in and of itself to prioritize a given grid cell/location. A change in the value of each of the other indicators had an unambiguous effect on its suitability as a location for infrastructure investments. For example an increase in the number of observed or potential trips always improves its suitability as a location for new infrastructure. The same is true for the number of collisions and the number of times a road segment in the grid cell was identified as a priority location. In the case of dangling nodes, however, there are other factors that influence its suitability or priority other than just the presence of the dangling node; factors such as how much infrastructure would need to be added in order for connectivity to be improved. As will be seen in the section 'Indicator Combinations 
and Specific Infrastructure Interventions,' connecting dangling nodes in some locations makes more sense than in others because of their context (e.g. proximity to other bike paths). As a result, the presence of dangling nodes was kept out of the prioritization index. This decision highlights the necessity of informed judgment on the part of the transportation professional or analyst, an essential element in planning any successful bicycle infrastructure.

\section{Visualizing Individual Indicators and the Prioritization Index}

Once the indicators are defined, associated with grid cells, and when appropriate aggregated and included in the prioritization index, they can be displayed cartographically. It is most appropriate to include not only grid cell data, but also the current location of cycling infrastructure. This analysis allows for a quick generalized view of the existing infrastructure and how it compares with high-priority locations.

It is useful first to visualize the differences in geographic distribution between each indicator as shown in Figure 3. From this, we can see that current cycling trips are highly concentrated in the downtown area and inner suburbs (Fig. 3a), with pronounced corridors running north-south between the Rivière-des-Prairies to the north and the St. Lawrence river to the south, and eastwest from the downtown. Also, short car trips are not limited only to suburban areas; central neighborhoods also generate large numbers of short car trips (Fig. 3b). The streets suggested by cyclists in the survey for future facilities are primarily busy arterials, many of which span the entire length or breadth of the study region (Fig. 3c). The crash data reveal that bicycle crashes are widely distributed across the island, with a concentration in the central areas (Fig. 3d). The dispersed distribution of bicycle crashes contrasts with the concentrated nature of existing bicycle usage, which suggests that the relationship between crashes and high cyclist volumes is not simply a function of cyclist exposure, and thus that there are some important safety issues to consider in more peripheral parts of the city. This would be a fruitful area of study for a focused study of bicycle accidents in Montreal. 

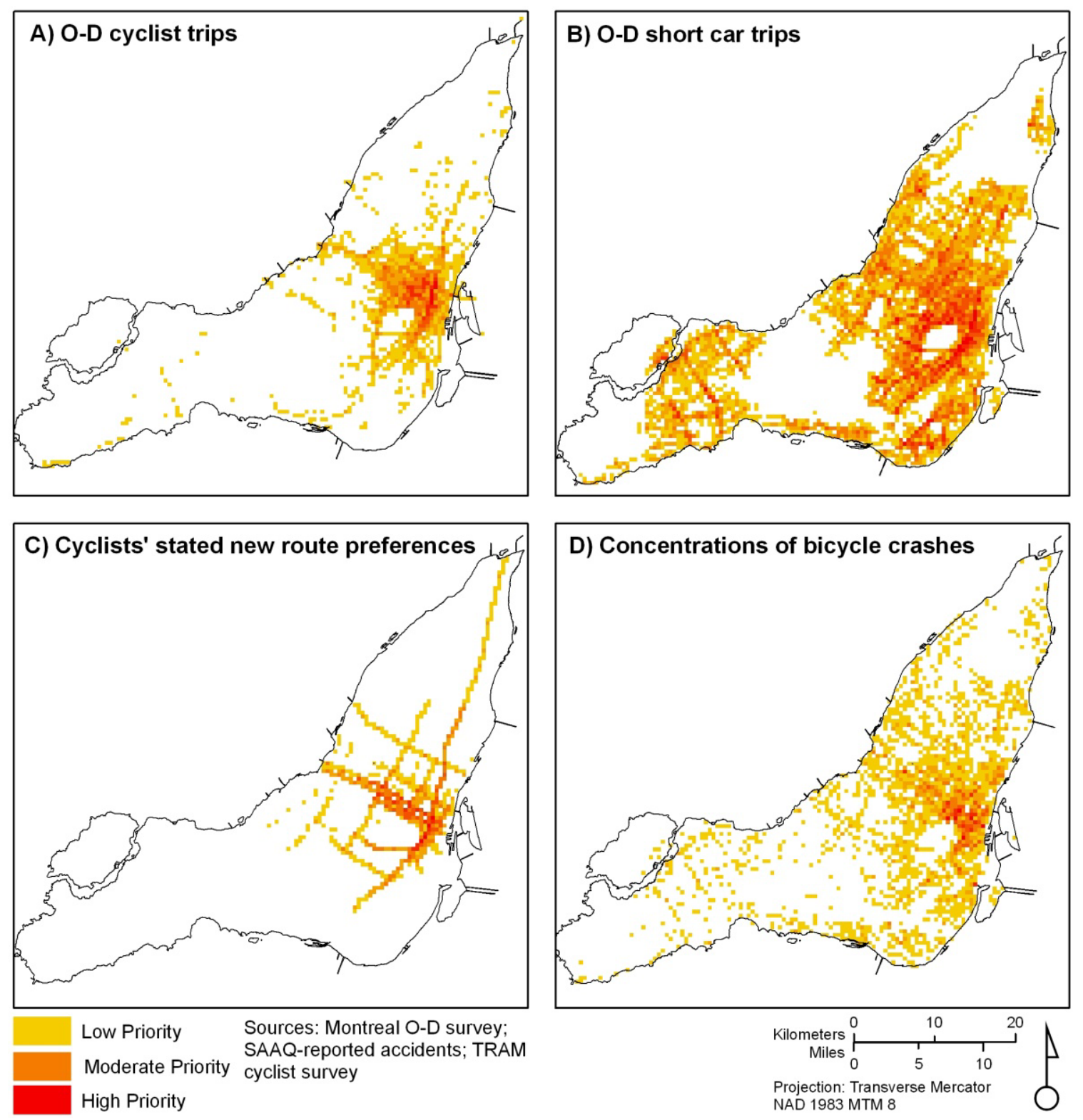

Figure 3. Measures for identifying potential locations for new facilities

The ease of aggregating various data inputs is the main advantage of the grid cell method. This is demonstrated when individual indicators are combined into the prioritization index (Fig. 4). The large frame area (Fig. 4a) shows the central section of the Island of Montreal; the embedded frame (Fig. 4b) shows part of the West Island suburbs. The areas identified could be considered as priority zones, where future investments in cycling infrastructure are likely to benefit the greatest number of current and potential cyclists. 

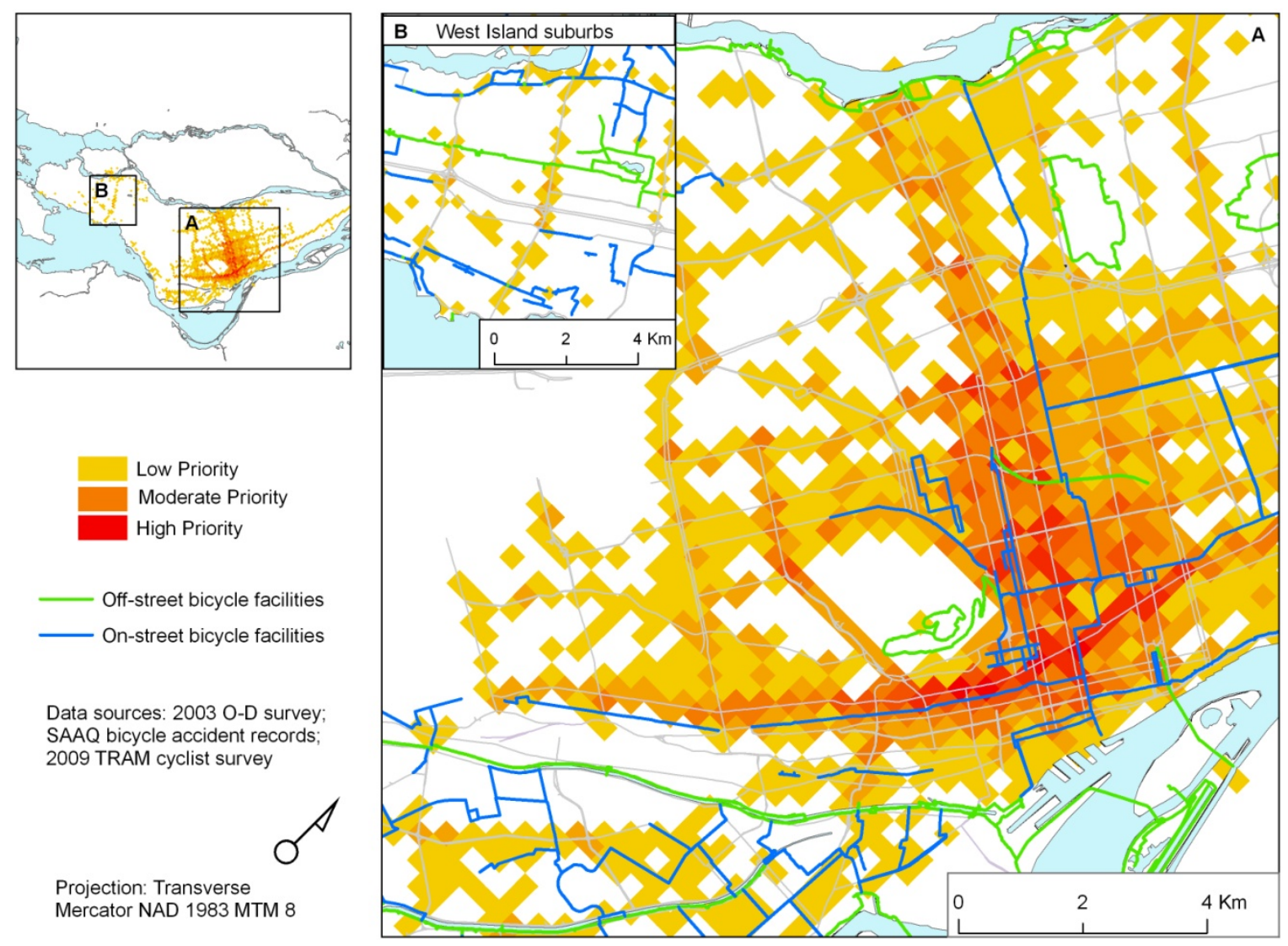

Figure 4. Combined measure identifying priority areas for new facilities

Observers can make several useful observations about the current state of Montreal's bicycle facilities, and can identify opportunities for future investment. The above figure shows that the West Island suburbs have several east-west bicycle facilities, however few north-south connections linking them together. Also, while there are many segments of bicycle facilities in the southwest quadrant of the city (Fig 4, bottom of frame), most do not follow major demand corridors. Furthermore, given several major demand corridors running north-south between the two rivers and high accident concentrations in the upper portion of the main frame, there is a strong argument for additional bicycle facilities in this area. Using streets with high concentrations of accidents and those specifically requested in the cyclist survey as a guide, this northwest area would benefit from several new bicycle facilities. As the grid cell method does not identify individual streets for new cycle facilities, final route selection should take into consideration the routes suggested by survey respondents as well as on-the-ground realities. 


\section{Indicator Combinations and Specific Infrastructure Interventions}

The prioritization index gives a general picture of where existing infrastructure is compared to highest priority locations. By considering particular combinations and contexts of the pertinent indicators, more specific interventions can be inferred. Table 1 provides a number of different contexts and combinations of the pertinent indicators. In particular, it shows combinations involving the presence of dangling nodes identifying discontinuities; the concentrations of crashes identifying safety issues; and the location and spatial continuity of high-priority (based on the prioritization index) grid cells all in different contexts (e.g. in the context of existing cycling infrastructure). Several of these combinations are also illustrated cartographically in Figure 5. Naturally, the list of combinations and contexts of the indicators in Table 1 is not exhaustive. It does serve, however, to demonstrate how this GIS approach can be used to infer different infrastructure interventions or non-interventions, as the case may be.

Table 1 - Using Indicators to infer cycling infrastructure interventions

\begin{tabular}{|c|c|c|c|c|}
\hline Comb. & Indicator & Context & Action recommended & Figure \\
\hline 1 & $\begin{array}{l}\text { High priority } \\
\text { corridor }\end{array}$ & $\begin{array}{l}\text { No cycling } \\
\text { facility }\end{array}$ & Build new facility & $5 a$ \\
\hline 2 & $\begin{array}{l}\text { High priority } \\
\text { corridor }\end{array}$ & $\begin{array}{l}\text { Existing cycling } \\
\text { facility }\end{array}$ & $\begin{array}{l}\text { Upgrade existing facility } \\
\text { and/or build parallel facility }\end{array}$ & - \\
\hline 3 & $\begin{array}{l}\text { Isolated high } \\
\text { value grid cell }\end{array}$ & Anywhere & $\begin{array}{c}\text { Improve cycling conditions; } \\
\text { new facility not necessarily } \\
\text { required }\end{array}$ & - \\
\hline 4 & $\begin{array}{l}\text { Concentration } \\
\text { of crashes }\end{array}$ & $\begin{array}{l}\text { High value grid } \\
\text { cell, no cycling } \\
\text { facility }\end{array}$ & Build new facility & $5 b$ \\
\hline 5 & $\begin{array}{l}\text { Concentration } \\
\text { of crashes }\end{array}$ & $\begin{array}{c}\text { Street with } \\
\text { cycling facility }\end{array}$ & $\begin{array}{l}\text { Field study of existing } \\
\text { conditions and possibly } \\
\text { upgrade existing facility }\end{array}$ & $5 c$ \\
\hline 6 & Dangling node & $\begin{array}{l}\text { High value grid } \\
\text { cell }\end{array}$ & $\begin{array}{l}\text { Connect to nearby facility } \\
\text { through high value square }\end{array}$ & $5 d$ \\
\hline 7 & Dangling node & $\begin{array}{l}\text { Low value grid } \\
\text { cell }\end{array}$ & Take no action & - \\
\hline
\end{tabular}


Consider a few examples. The first combination of indicator and context refers to a series of connected grid cells with high values of the prioritization index, where there is currently no cycling infrastructure. A situation like this from Montreal can be found in Figure 5a. In this map there are two intersecting corridors (identified by hashed ellipses), one along a northwest axis and the other along northeast axis. Along neither of these corridors is there any cycling infrastructure. The presence of a corridor of high-priority grid cells without any cycling infrastructure is a perfect example of how this method could be used to infer (and identify the location for) new infrastructure to better supply existing cycling demand.

The fourth combination refers to a situation with high-priority grid cells where there is also a concentration of bicycle/automobile collisions and no cycling infrastructure. Figure 5b shows such a combination in Montreal. The street in question runs to the northwest and is identified by a hashed ellipse. It is surrounded by a series of high priority grid cells and has been the location for a number of crashes. This is another very good example of how the method can be used to infer the appropriate location for infrastructure aimed at reducing bicycle/automobile crashes.

The fifth combination refers to a situation where a high concentration of crashes coincides with existing infrastructure. Such is the case in Figure 5c. Here crashes have been reported at every intersection along a $1.5 \mathrm{~km}$ stretch of cycling infrastructure. From this it can be inferred that there are safety concerns and that the area should be studied for the possibility of an infrastructure upgrade also to reduce bicycle/automobile crashes.

A final example is combination 6, where dangling nodes are found in high-priority grid cells. Figure $5 \mathrm{~d}$ shows a number of locations in Montreal demonstrating this combination. In fact, there are two concentrations of dangling nodes highlighted in the map, both identified by hashed ellipses along northwest axes. The ellipse to the northwest shows three dangling nodes of three bicycle paths that are quite close together. Moreover, the dangling nodes project out towards other bicycle paths. The ellipse to the southeast, however, shows four different dangling nodes. Each of these dangling nodes are on vectors that either don't project towards other bicycle paths, or that project towards other bicycle paths much further away than the concentration of nodes in the northwest ellipse. 

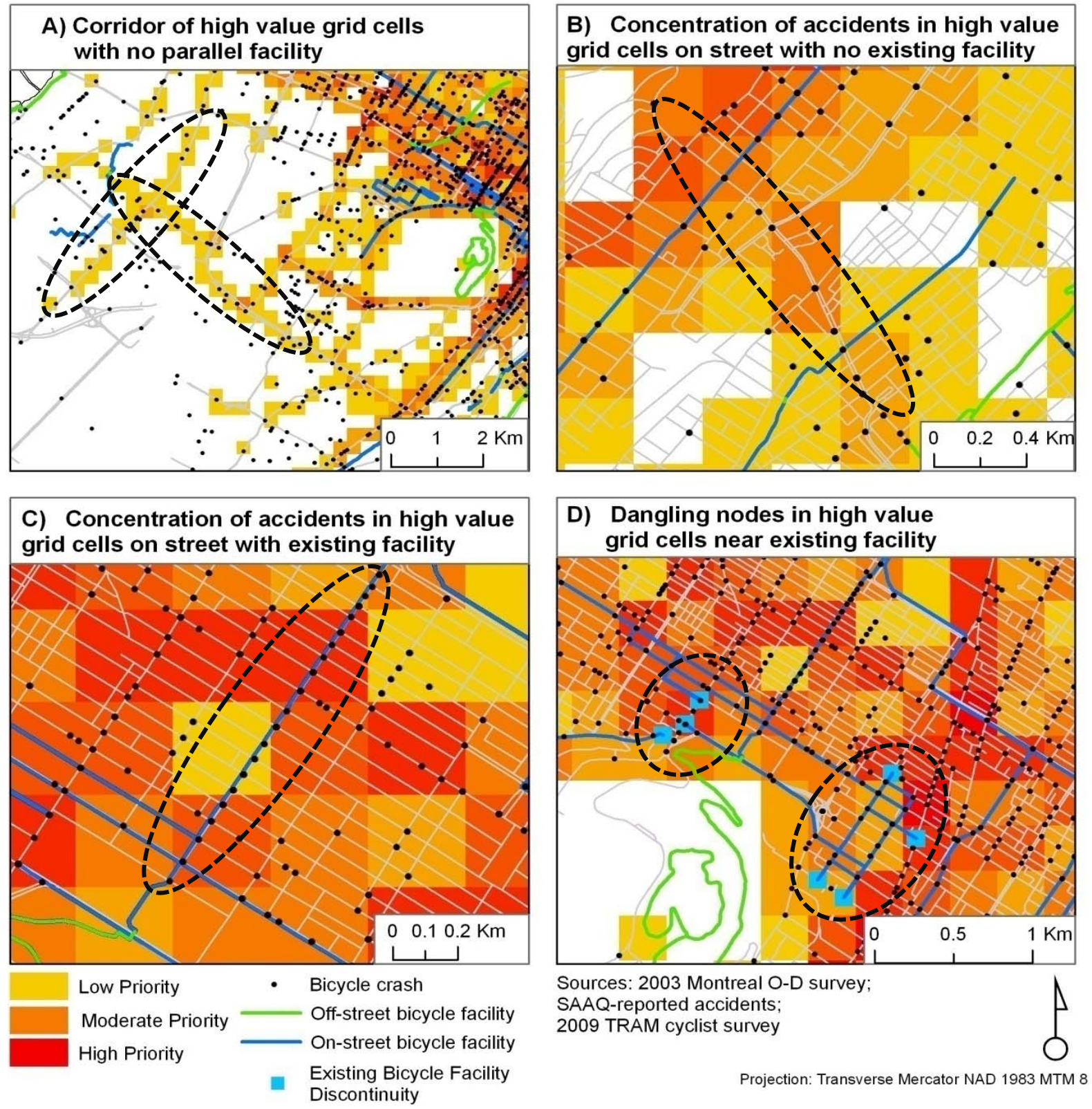

Figure 5. Specific situations identified by the proposed methodology

This comparison is made for three reasons. First, we see that both concentrations represent highpriority grid cells and dangling nodes from which we can infer the suitability of infrastructure investments to improve connectivity of the existing bicycle path system. Second, we can also infer that investments in infrastructure in the northwestern ellipse would be much more efficient in improving connectivity than in the southeastern ellipse. Connecting the three disconnected 
bike paths in the NW ellipse would involve relatively minor interventions. Connecting dangling nodes to other paths in the SE ellipse would involve more consequential interventions. Third, this illustrates why dangling nodes were not included in the prioritization index, and why it was more appropriate to include them as part of a visual analysis in addition to the PI. The inclusion of dangling nodes would not be able to communicate how one intervention could be more effective in increasing the connectivity of the existing system.

\section{Discussion and Conclusion}

As cities turn increasingly to bicycles to carry a greater proportion of short distance trips, it is crucial that planners have systematic empirical methods and reliable tools with which to plan new facilities. Using Montreal as a case study, this paper represents one effort to develop such a methodology. By using grid cells and several data sources in a balanced analysis, it shows how GIS can be used to help effectively plan additions to an existing bicycle network. The datasets used in this paper were: 1) 'observed' bicycle trips; 2) 'potential' bicycle (short car) trips; 3) segments of bicycle paths suggested by survey respondents as being high priority; 4) bicyclevehicle collision data; and 5) the presence of 'dangling nodes', or bicycle facilities that end abruptly.

In the analysis presented here, five different indicators were used to demonstrate how to prioritize different possible cycling infrastructure investments. The indicators are not an exhaustive list of those that could be incorporated. One could easily imagine others that could/should be incorporated in such an analysis: indicators such as accessibility to important activity generators, among others. That said, the intention of the paper was to describe the methodology in sufficient detail to demonstrate how it can be used, as well as to show flexibility in being able to incorporate other indicators.

In this study we used the 300 meter grid cells, since we found them to be most appropriate to the Montreal region. The method developed in this research paper recommends general areas in a region where facilities are needed, and is particularly well-suited for identifying priority corridors. Other grid cell sizes should be tested when implementing this methodology in other 
regions. This method should be followed by detailed analysis of alternative routes within the zones identified as high priority for new cycling infrastructure.

Applying this method to the Island of Montreal, we see a considerable demand for new cycling facilities throughout most of the central city and for specific corridors in the West Island suburbs and in the area north of the Mount Royal. In the center of the city, our methodology suggests several parallel cycling facilities running north-south to provide alternatives to the sole path that traverses the island in this direction. Likewise, new east-west facilities are recommended to augment the existing network, and extend further west, connecting high demand areas west and north of the Mount Royal. By simply focusing on building a consolidated network in the area highlighted in figure 4, Montreal's cycling network would be significantly improved. In general, greater emphasis should be placed on connectivity when designing a cycling network.

Overall, this work raises a number of important data, measurement, and methodological issues for future research in cycling infrastructure. It is important to note that since this methodology involves multiple data sources with no defined weighting technique, decisions about the relative importance of each of these factors must be made by the analyst. Moreover, an understanding of cyclists travel behavior is necessary to accompany the implementation of such methodology. While this type of analysis is useful for identifying opportunity zones, allowing transportation planners to establish macro-level priorities, given the assumptions made about actual route choice, this approach is not appropriate for detailed analysis. The grid cell method is used in this paper for locating bicycle facilities; however it can also be applied to locate other cycling facilities such as bicycle parking or public bicycle stations. The data required for locating these points would be different from that required for new cycling facilities; however the principle remains the same. It needs to be mentioned again that while the method could be applied in isolation, it would be much more effectively applied in the context of a higher-level conceptual plan. Within such a context the tool could effectively be used to prioritize and select different infrastructure investment options bound to appear as the result of a higher-level plan. 
Given the demonstrated importance of cycling infrastructure in encouraging cycling as a mainstream form of active transportation, methods which objectively reveal priority areas are necessary to ensure that the finite resources devoted to cycling infrastructure are well-used. The method described in this paper offers what we consider a promising approach. However, as cities implement new facilities and enhance existing ones, it will be important to develop posterior evaluative methods to determine the success of various interventions. After all, sustained public support will depend on the demonstrated success of a given intervention. Clear justifications for new cycling infrastructure and objective evaluation of past projects will result in a greater degree of transparency in transportation planning, and ultimately better planned cycling networks.

\section{ACKNOWLEDGMENTS}

First of all we would like to thank the Montreal cycling community for their support and help in distributing and filling the Montreal cycling survey. Without their help this paper would have never came to reality. This research funded by the National Science and Engineering Research Council of Canada (NSERC) Discovery Grant and the Canada Foundation for Innovation (CFI). We would like to thank Prof. Luis Miranda-Moreno for providing the accident data used in the analysis. Last but not least we would like thank Mr. Daniel Bergeron of the AMT for providing the Montreal OD survey used in the analysis. All opinions and errors in this paper are the responsibility of the authors. 


\section{REFERENCES}

Abraham, J., S. McMillan, et al. (2002). Investigation of cycling sensitivities. 81st Annual Meeting of the Transportation Research Board, Washington, DC, Transportation Research Board.

Agence métropolitaine de transport (2003). Enquête origine-destination 2003. Montréal, QC.

Allen-Munley, C., J. Daniel, et al. (2004). "Logistic model for rating urban bicycle route safety." Transportation Research Record(1878): 107-115.

Aultman-Hall, L., F. Hall, et al. (1997). "Analysis of bicycle commuter routes using geographic information systems: Implications for bicycle planning." Transportation Research Record(1578): 102-110.

Aultman-Hall, L. A. (1996). Communter bicycle route choice: Analysis of major determinants

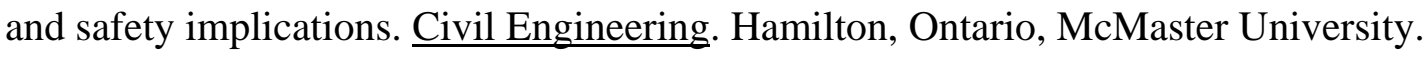
Ph.D: 224.

Baromètre (2005). Sondage auprès des Montréalais. Plan de Transport. Montreal.

Broach, J., J. Gliebe, et al. (2011). Bicycle route choice model developed using revealed preference GPS data. Annual Meeting of the Transportation Research Board, Washington, DC, Transportation Research Board.

Cervero, R., O. L. Sarmiento, et al. (2009). "Influences of Built Environments on Walking and Cycling: Lessons from Bogota." International Journal of Sustainable Transportation 3: 203-226.

Dill, J. and T. Carr (2003). "Bicycle commuting and facilities in major U.S. Cities: If you build them, commuters will use them." Transportation Research Record(1828): 116-123.

Dillman, D., J. Smyth, et al. (2009). Internet, mail and mixed-mode surveys: The tailored design method, third edition. Hoboken, NJ, John Wiley and Sons, Inc.

Forrester, J. (2001). "The bicycle transportation controversy." Transportation Quarterly 55(2): 717.

Garrarda, J., G. Roseb, et al. (2008). "Promoting transportation cycling for women: The role of bicycle infrastructure." Preventative Medicine 46(1): 55-59.

Handy, S. L. and Y. Xing (2011). "Factors correlated with bicycle commuting: a study in six small U.S. cities." International Journal of Sustainable Transportation 5(91-110). 
Hopkinson, P. and M. Wardman (1996). "Evaluating the demand for new cycle facilities." Transport Policy 3(4): 241-249.

Horner, M. W. and T. H. Grubesic (2001). "A GIS-based planning approach to locating urban rail terminals " Transportation 28: 55-77.

Hunter, W., D. Harkey, et al. (2000). "Evaluation of blue bike-lane treatment in Portland, Oregon." Transportation Research Record 1705: 107-115.

Jensen, S. (2007). "Safety effects of blue cycle crossings:A before-after study." Accident Analysis and Prevention 40: 742-750.

Krizek, K. (2007). Estimating the economic benefits of bicycling and bicycle facilities: An interpretive review and proposed methods. Essays on Transportation Economics. V. Inglada. Leipzip, Germany, Physica-Verlag HD.

Krizek, K., A. El-Geneidy, et al. (2007). "A detailed analysis of how an urban trail system affects the travel of cyclists." Transportation 34(5): 611-624.

Krizek, K. and R. Roland (2005). "What is at the end of the road? Understanding discontinuities of on-street bicycle lanes in urban settings." Transportation Research D 10(1): 55-68.

Landis, B., V. Vattikuti, et al. (1997). "Real-time human perceptions: Toward a bicycle level of service." Transportation Research Record (1578): 119-126.

Larsen, J. (2010). Beyond the Bike Lane: An Analysis of Cyclists' Travel Behavior in Montreal \& A Methodology for Locating New Routes. School of Urban Planning. Montreal, McGill University. Master's: 53.

Larsen, J. and A. El-Geneidy (2011). "A travel behavior analysis of urban cycling facilities in Montréal Canada." Transportation Research Part D: Transport and Environment, 16(2): 172-177.

Lusk, A. C., P. G. Furth, et al. (2011). "Risk of injury for bicycling on cycle tracks versus in the street." Injury Prevention.

Mackett, R. L. (2001). "Policies to attract drivers out of their cars for short trips " Transport Policy 8(4): 295-306.

McNeil, N. (2011). Bikeability and the Twenty-Minute Neighborhood: How Infrastructure and Destinations Influence Bicycle Accessibility. 90th Annual Meeting of the Transportation Research Board, Washington, D.C.

Montréal, V. d. (2007). Plan de Transport. 
Moudon, A., C. Lee, et al. (2005). "Cycling and the built environment, a US perspective." Transportation Research Part D 10(3): 245-261.

Nelson, A. and D. Allen (1997). "If you build them, commuters will use them: The association between bicycle facilities and bicycle commuting

" Transportation Research Record(1578): 79-83.

Noland, R. B., D. Deka, et al. (2011). "A statewide analysis of bicycling in New Jersey." International Journal of Sustainable Transportation 5(251-269).

Ortuzar, J., I. Iacobell, et al. (2000). "Estimating demand for a cycle-way network." Transportation Research Part A 34(5): 353-373.

Parkin, J., T. Ryley, et al. (2007). Barriers to cycling: an exploration of quantitative analyses. Cycling and Society. P. Rosen, P. Cox and D. Horton. Burlington, VT, Ashgate.

Parkin, J., M. Wardman, et al. (2007). "Models of perceived cycling risk and route acceptability." Accident Analysis \& Prevention 39(2): 364-371.

Parkin, J., M. Wardman, et al. (2007). "Models of perceived cycling risk and route acceptability." Accident Analysis and Prevention 39: 364-371.

Pucher, J. (2008). "Cycling for Everyone: Lessons from Europe " Transportation Research Record 2074: 58-65.

Pucher, J., C. Komanoff, et al. (1999). "Bicycling renaissance in North America? Recent trends and alternative policies to promote bicycling." Transportation Research Part A 33(7/8): 625-654.

Ryan, S. J. and W. M. Getz (2005). "A spatial location-allocation GIS framework for managing water sources in a savanna nature reserve." South African Journal of Wildlife Research 35(2): 163-178.

Yeh, A. G. and M. H. Chow (1996). "An integrated GIS and location-allocation approach to public facilities planning-An example of open space planning." Computers, Environment and Urban Systems 20(4-5): 339-350. 